\title{
Decision working medium for lower cycle CCGT trinary type
}

\author{
Sviatoslav Tsibulskiy ${ }^{1, *}$, Nikolay Galashov ${ }^{1}$, Al'bina Bannova ${ }^{1}$, Denis Melnikov ${ }^{1}$, and \\ Alexander Kiselev ${ }^{1}$ \\ ${ }^{1}$ National Research Tomsk Polytechnic University, 634050 Tomsk, Russia
}

\begin{abstract}
The object of the study are low-boiling substances, which can be used as working fluid in the Organic Rankine cycle (ORC) combine cycle gas turbine (CCGT) trinary type. Purpose of research is search for substances with the best thermodynamic, thermophysical and ecological properties. The calculation algorithm represents a mathematical calculation of CCGT in which the lower cycle, operating on low-boiling fluid and utilizes low-potential heat, as an air-cooling device On the basis of available scientific and practical facts on the use of working fluids the organic Rankine cycle for analysis were selected ozone-safe refrigerant: butane, pentane, R236ea, R236fa, R123, R245ca, R245fa, R365mfc, RC318. For these substances were found and tabulated critical pressure and temperature, condensation pressure, density and dynamic viscosity at a given condensation temperature. Studies have shown that the highest thermal net efficiency is achieved when using natural Freon pentane and synthetic R365mfc. Net efficiency CCGT strongly depends on the condensation temperature of the substance. For example, when using pentane when the condensation temperature decreases on $10{ }^{\circ} \mathrm{C}$ net efficiency increases about $0.71 \%$.
\end{abstract}

\section{Introduction}

The most perfect are recycling three-circuit CCGT with intermediate steam superheat on the based the most powerful gas turbine unit (GTU) General Electric GE 9HA.02 with nominal electric power $544 \mathrm{MW}$ and net efficiency $43.9 \%$ can achieve summary net efficiency $63.5 \%$ when arrangement 1GTU+1STU (steam turbine unit) or $63.7 \%$ when arrangement $2 \mathrm{GTU}+1 \mathrm{STU}$ [1]. At the same time, all the possibilities of improving the CCGT equipment were used, and when consume water steam as a working fluid in the steam turbine plant, further increase in the efficiency of the CCGT is practically impossible. This is due to the fact that the heat removal temperature in the condenser during the operation of the STU with water vapor is limited by the freezing point of water $-0{ }^{\circ} \mathrm{C}$, due to economic conditions, is usually not lower $15^{\circ} \mathrm{C}$.

\footnotetext{
* Corresponding author: s.tzibulsky@yandex.ru
} 
In the north regions, where the air temperature for a long time is lower $0{ }^{\circ} \mathrm{C}$, it is possible to lower the heat removal temperature in the cycle using instead of water air capacitors (AC), and as a working fluid to use substances, that do not freeze at low temperatures, which are used in the organic Rankine cycle (ORC). But these substances are destroyed at temperatures above $400{ }^{\circ} \mathrm{C}$. Therefore, a CCGT of a trinary type was proposed on the basis of three cycles: higher - Brighton gas turbine cycle, average - Rankine cycle steam turbine and lower - ORC [2-6]. The use of low-boiling substances (LBS) in ORC makes it possible to reliably remove heat in the $\mathrm{AC}$ at the temperature below $0{ }^{\circ} \mathrm{C}$ [7], allows downsizing and installation costs of the turbine and condenser, and also makes it possible to significantly reduce water consumption for technological purposes.

The ecological purity of Freon is determined by the potential for ozone depletion (ODP) and the potential of global warming GWP.

\section{Selection of substances and analysis based on the REFPROP}

In this paper, for the analysis and selection of the LBS for the ORC use the base "REFPROP" [8], which allows us to calculate the thermodynamic and thermophysical properties of most substances used in production processes.

At present, low-boiling substances are divided into 4 groups: ozone-depleting chlorofluorocarbons and hydrochlorofluorocarbons, transient hydrofluorocarbons, ozonefriendly hydrofluorocarbons and natural.

For research based on the analysis of available publications [9-10] and the requirements for working fluids the following Freon were chosen: pentane, butane, R365mfc, RC318, R236ea, R236fa, R123, R245ca, R245fa. These Freon have a low potential for ozone depletion. The remaining Freon are not flammable, but they have a significant GWP. All the selected Freon have a positive slope of the saturated vapor boundary curve, so the process in the turbine will pass in the superheated steam and after the turbine it is required to install the desuperheater.

For selected substances in the table 1-2 are given the thermophysical and thermodynamic parameters determined on the basis of the "REFPROP", where designation of parameters following: $\mathrm{M}$ - molecular mass; $t_{\mathrm{TP}}-$ temperature of triple point; $t_{0}-$ temperature boiling point at atmospheric pressure $98 \mathrm{kPa} ; t_{\mathrm{CR}}-$ critical temperature; $P_{\mathrm{CR}}-$ critical pressure; $\rho_{\mathrm{CR}}-$ critical density; $\xi$ - the value of the derivative $d T / d S$ on the saturated vapor line; GWP - global warming potential.

Table 1. Properties of ozone-safe refrigerant.

\begin{tabular}{|l|c|c|c|c|c|c|}
\hline Refrigerant & $\begin{array}{c}\mathbf{M}, \\
\mathbf{g} / \mathbf{m o l}\end{array}$ & $\begin{array}{c}\boldsymbol{t}_{\mathbf{T P}}, \\
{ }^{\mathbf{C}} \mathbf{C}\end{array}$ & $\begin{array}{c}\boldsymbol{t}_{\mathbf{0}} \mathbf{\boldsymbol { }} \\
{ }^{\circ} \mathbf{C}\end{array}$ & $\begin{array}{c}\mathbf{\rho}_{\mathbf{C R}}, \\
\mathbf{m o l} / \mathbf{l}\end{array}$ & $\begin{array}{c}\boldsymbol{\xi}, \\
\mathbf{J} /\left(\mathbf{k g} \cdot \mathbf{K}^{2}\right)\end{array}$ & $\mathbf{G W P}$ \\
\hline R236ea & 152 & - & 6.5 & 3.70 & 1.39 & 1200 \\
\hline R236fa & 152 & -93 & -1 & 3.70 & 0.76 & 8000 \\
\hline R123 & 153 & -107 & 28 & 3.60 & 2.76 & 90 \\
\hline R245ca & 134 & - & 25 & 3.91 & 1.38 & 610 \\
\hline R245fa & 134 & -102 & 15 & 3.85 & 0.19 & 950 \\
\hline R365mfc & 148 & -34 & 40 & 3.20 & 0.86 & $<1500$ \\
\hline RC318 & 200 & -40 & -7 & 3.10 & 1.12 & 9100 \\
\hline butane & 58 & -138 & -1 & 3.92 & 1.03 & 3 \\
\hline pentane & 72 & -130 & 36 & 3.22 & 1.51 & 11 \\
\hline
\end{tabular}

The lowest value of the global warming potential is possessed by natural Freon: pentane and butane, further along the increasing go: R123, R245ca, R245fa, R236ea, R365mfc, R236fa and RC318. All considered Freon have a triple point temperature lower $-30^{\circ} \mathrm{C}$, 
which determines their reliable operation in the winter and the possibility of heat removal in the air condenser at very low temperatures. All Freon have $\xi$ close to 0 , which ensures their operation in the turbine without loss of moisture.

High temperature of boiling points $\left(\mathrm{t}_{0}\right)$ at atmospheric pressure have following Freon (in decreasing order): pentane, R365mfc, R123, R245ca. This indicator characterizes below what temperature in the condenser there is a vacuum.

A number of operational parameters for selected substances are given in the table $2 . \mathrm{P}_{\mathrm{CR}}$ and $\mathrm{t}_{\mathrm{CR}}-$ critical properties steam of Freon; $\mathrm{P}_{\mathrm{C}}-$ condensation pressure at temperature $15^{\circ} \mathrm{C} ; \rho, \lambda$-density and dynamic viscosity of liquid at temperature $15^{\circ} \mathrm{C}$.

Table 2. Operational characteristics of refrigerant.

\begin{tabular}{|c|c|c|c|c|c|c|}
\hline Refrigerant & $\mathbf{P}_{\mathbf{C R}}, \mathbf{M P a}$ & $\mathbf{t}_{\mathbf{C R}},{ }^{\circ} \mathbf{C}$ & $\mathbf{P}_{\mathbf{C}}, \mathbf{M P a}$ & $\boldsymbol{\rho}, \mathbf{k g} / \mathbf{m}^{\mathbf{3}}$ & $\boldsymbol{\lambda}, \mathbf{m P a} \cdot \mathbf{s}$ & $\boldsymbol{\rho} \cdot \boldsymbol{\lambda} \cdot \mathbf{1 0}^{\mathbf{5}}$ \\
\hline R236ea & 3.50 & 139.29 & 0.143 & 1455.78 & 440.90 & 6.42 \\
\hline R236fa & 3.20 & 124.85 & 0.101 & 1392.75 & 324.29 & 4.52 \\
\hline R123 & 3.66 & 183.68 & 0.062 & 1489.18 & 469.61 & 6.99 \\
\hline R245ca & 3.925 & 174.42 & 0.0676 & 1411.07 & 621.54 & 8.77 \\
\hline R245fa & 3.651 & 154.01 & 0.1007 & 1365.27 & 464.27 & 6.34 \\
\hline R365mfc & 3.266 & 186.85 & 0.0372 & 1278.10 & 463.22 & 5.92 \\
\hline RC318 & 2.777 & 115.23 & 0.224 & 1537.76 & 420.39 & 6.46 \\
\hline butane & 3.769 & 152.00 & 0.18 & 584.25 & 174.39 & 1.02 \\
\hline pentane & 3.370 & 196.55 & 0.05 & 630.56 & 237.45 & 1.50 \\
\hline
\end{tabular}

The highest values of critical temperatures are pentane, R365mfc, R123.

The lowest values of viscosity-density characteristics have (with increasing): butane, propane, R236fa, R365mfc, R245fa, R236ea, RC318, R123, R245ca.

\section{Investigation of the thermal scheme of a combined-cycle plant}

For research on the selection of Freon for the ORC was developed the basic thermal scheme of a combined-cycle plant of the trinary type (fig.1).

The installation works as follows. In the GTU cycle, compressed air in the compressor enters the combustion chamber, where fuel is supplied (gas). Combustion products are sent to the gas turbine, the flow passes through the part where the commit operation. Then the combustion products are sent to the waste heat boiler, where heat is given to water and Freon. Steam-water mixture is formed in the evaporator of the waste heat boiler. Saturated steam separates from the mixture in the blow case. Steam after overheating in a superheater with temperature $t_{0}$ enters the high-pressure cylinder (HPC) of the steam turbine (ST) and performs work on the shaft. The steam after the HPC is enters to the condenser -evaporator (CE), where it transfers heat to the Freon and condenses to the saturation state of the liquid. The water condensate is fed by a feed pump (FP1) through the economizer (EC1) into the drum and the steam-water cycle closes. Freon steam from CE enters in low pressure cylinder (CLP) turbine, performs work and, through a desuperheater (DH), is condensed into an air condenser (AC). LBS condensate by condensate pump (CP) is fed through a DH to heat its own stream of superheated steam into a regenerative heater $(\mathrm{RH})$. In the $\mathrm{RH}$ receives Freon steam from the regenerative bleeding off LPC and heats the condensate to the required temperature $60{ }^{\circ} \mathrm{C}$. Heated condensate with a feed pump (FP2) is pumped through an economizer (EC2), where it is heated by combustion products. The condensate is fed into the CE of ORC and the cycle is closed. Exhaust gas are diverted to the chimney. The work received through turbines GTU and STU through the shaft is transmitted to the power generator, where electricity is generated. 


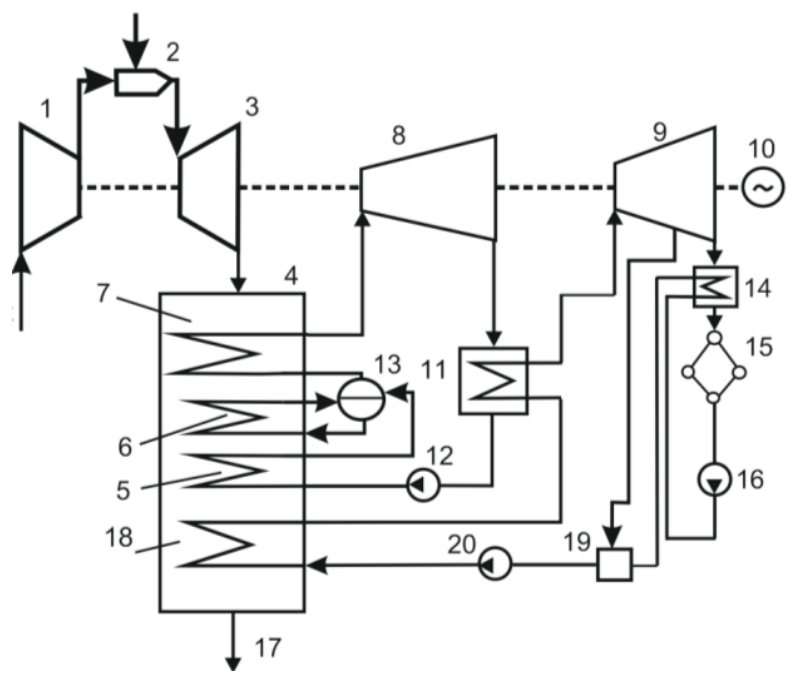

Fig. 1 - The basic thermal scheme of a combined-cycle gas turbine of the trinary type: 1 - basic air compressor (AC), 2 - combustion chamber (CC), 3 - gas turbine (GT), 4 - heat-recovery steam generator (HRSG), 5 - water economizer (EC1), 6 - evaporator (E), 7 - superheater $(\mathrm{SH}), 8,9$ - high and lower pressure cylinders HPC and LPC, 10 - electric generator (EG), 11 - condenser-evaporator (CE), 12 - feed pump (FP1), 13 - blow case (B), 14 - desuperheater (DH), 15 - air condenser (AC), 16 - Freon condensate pump (CP), 17 - exhaust gases, 18 - Freon economizer (EC2), 19 regenerative heater $(\mathrm{RH}), 20$ - Freon feed pump (FP2).

\section{Analysis of the results of the algorithm for calculating the thermal diagram on the bases REFPROP}

Based on this diagram (fig. 1) was developed

mathematical algorithm for calculating the performance of CCGT of a trinary type. The algorithm is implemented by the program in an Excel spreadsheet package. Calculations of the properties of all substances in the program are performed on the basis of the functions of the database "REFPROP" [4].

The calculations are based on the following data.

Cycle GTU based on the turbine GE 9HA.02: electricity power $544 \mathrm{MW}$; net efficiency $43.9 \%$; gas flow rate and temperature at the entrance to the HRSG $986.89 \mathrm{~kg} / \mathrm{s}$ и $636{ }^{\circ} \mathrm{C}$; temperature of the Freon inlet in the economizer $60^{\circ} \mathrm{C}$, temperature of exhaust gases $100^{\circ} \mathrm{C}$.

Steam-water cycle: temperature and pressure at the inlet to the HPC $610^{\circ} \mathrm{C}$ and 18 $\mathrm{MPa}$, pressure of water steam after HPC $0.2 \mathrm{MPa}$.

ORC: Freon saturation temperature into $\mathrm{CE} 109.9^{\circ} \mathrm{C}$; Freon condensing temperature AC $-20 \div+20^{\circ} \mathrm{C}$.

The results obtained from the studies of efficiency gross and net is dependent on the condensation temperature and Freon type in the fig. 2.

In fig. 2 that the efficiency of the CCGT depends essentially on the condensation temperature and the type of Freon. The type of Freon strongly affects the efficiency of the CCGT. This is due to the cost of own needs due to the increased density, viscosity and pressure. Of the Freon considered according to the efficiency of CCGT net, the best is pentane, in second place is R365mfc, followed by R123 and R245ca. For pentane, a decrease in the condensation temperature by $10{ }^{\circ} \mathrm{C}$ increases the efficiency of gross and net $0.71 \%$. 
The conducted studies show that when ORC on pentane or R365mfc CCGT is used, the trinary type at a condensation temperature below $0{ }^{\circ} \mathrm{C}$ will surpass the net efficiency of a three-circuit CCGT running on water.

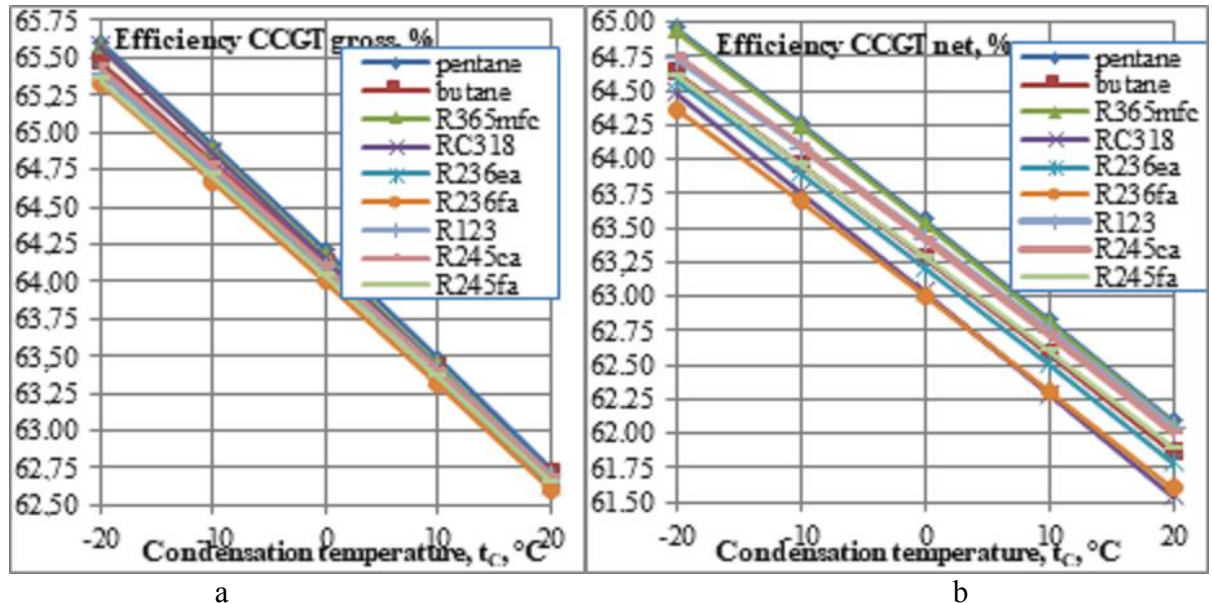

Fig. 2. Dependence efficiency CCGT gross (a) and net (b) on the condensation temperature of Freon in $\mathrm{AC}$.

\section{References}

1. URL: https://www.gepower.com/gas/gas-turbines/9ha.

2. N.N. Galashov, S. A. Tsybulsky, Power Technology and Engineering, 48, 6 (2015), DOI: $10.1007 / \mathrm{s} 10749-015-0555-9$

3. K. Larionov, D. Gvozdjakov, A. Zenkov, V. Zaytsev, EPJ Web of Conferences, 110, 01034 (2016), DOI: 10.1051/epjconf/201611001034

4. O. Romashova, L. Belyaev, A. Tubolev, E. Skrebatun, MATEC Web of Conferences, 91, 01009 (2016) DOI: 10.1051/matecconf/20179101009

5. O. Romashova, A. Minor, V. Martyshev, A. Tubolev, A. Katalevskaya, MATEC Web of Conferences, 110, 01054 (2017), DOI: 10.1051/matecconf/201711001054

6. S. Yankovskiy, A. Matveev, A. Tolokolnikov, A. Zenkov, MATEC Web of Conferences, 92, 01036 (2016), DOI: 10.1051/matecconf/20179201036

7. N.N. Galashov, S.A. Tsibul'ski, Power Technology and Engineering, 49, 5 (2016), DOI: 10.1007/s10749-016-0629-3

8. E.W. Lemmon, M.L. Huber, M.O. McLinden, Reference fluid thermodynamic and transport properties-REFPROP, standard reference database 23, version 8.0, National Institute of Standard and Technology (2007)

9. B.N. Maksimov, V.G. Barabanov, I.L. Serushkin, Industrial fluororganic products: reference edition (St. Petersburg: Chemistry, 1996)

10. Freons: types and properties. URL: http://www.newchemistry.ru/letter.php?n_id=817 